\title{
Sodium Nitrate Supplement
}

National Cancer Institute

\section{Source}

National Cancer Institute. Sodium Nitrate Supplement. NCI Thesaurus. Code C131823.

A dietary supplement containing sodium nitrate, that can be used for nitrate

supplementation purposes. Upon oral administration, nitrate is absorbed by the body and

is partially converted to nitrite, which is stored and circulated in the blood, leading to an increase in nitrite levels. Nitrate, and to some extent nitrite, accumulates in saliva and may enhance salivary flow, which may help to treat dry mouth and chemo- and radiationinduced oropharyngeal problems. 